feeds were examined, and available infant 6 week weight measurements recorded.

Results In total, 368 (81.8\%) mothers provided any formula milk to their infants at 6 weeks; of these, 14 (3.8\%) reported to adding solid foods to their infant's bottle feeds. Almost $50 \%$ of formula feeding mothers $(n=181)$ reported to changing their infant's formula type/brand at least once during the first 6 weeks, mainly due to increased hunger and feeding frequency (2-3 hourly) (54.8\%). Where 6 week infant weight measurements were available $(n=$ 184), a mean of $205 \mathrm{ml}$ (SD $45 \mathrm{ml}$ ) of formula milk/kilogram body weight/day was consumed by these infants.

Conclusion Several formula feeding practices with potential implications for later obesity risk were identified in this study including premature introduction to solids ( $\leq 6$ weeks) and consumption of excessive formula milk volumes at 6 weeks relative to infant feeding guidelines. Early provision of recommended feeding guidelines including specific advice on age-appropriate milk volumes to parents who formula feed should be considered in obesity prevention programmes.

\section{THE GROWTH AND NOURISHMENT OF PUPIL POPULATION IN THE MUNICIPALITY OF NOVI SAD IN SCHOOL YEARS 2010/2011 AND 1996/1997- COMPARISON}

doi:10.1136/archdischild-2012-302724.1449

'M Hadnadjev, 'M Budakov, ${ }^{2} \mathrm{D}$ Hadnadjev, 'M Bratic. 'Paediatrics Department, Health Centre Novi Sad; ${ }^{2}$ Center for Radiology, Clinical Center Vojvodina, Novi Sad, Serbia

Purpose to examine the growth and nourishment of the school children in Novi Sad, in the school year 2010/2011 and 1996/1997 and determine differences in growth and nourishment between two school year periods.

Methods During regular health checks in primary and secondary schools in Novi Sad, we registered a total number of children with average height (from $-1.5 \mathrm{SD}$ to $+1.5 \mathrm{SD})$, tall $(+2 \mathrm{SD},+3 \mathrm{SD})$, short ( $-2 \mathrm{SD},-3 \mathrm{SD}$ ), with normal weight (from $-0.5 \mathrm{SD}$ to $+1 \mathrm{SD})$, obese $(+1.5 \mathrm{SD}$ to $+3 \mathrm{SD}$ ), and thin pupils (from $-1.5 \mathrm{SD}$ to $-3 \mathrm{SD}$ ).

Results From the total of 40861 pupils (7-19 years) in school year 2010/2011, we examined 15222 (37.25\%):11095 (41.52\%) in primary and 4127 (29.19\%) in secondary schools, and in school year $1996 / 1997$, from the total of 23248 enrolled pupils, 20704 (89.05\%) were examined, in primary schools 12135 (94.80\%) and in secondary schools 8569 (82.01\%).

After comparing data from primary and secondary schools, in the school year 20010/2011, a statistically significant difference was in favor of primary school children, where there was the number of obese children $(p=0.000)$ and thin children $(p=0.000)$ in $2010 / 2011$, while the number of obese children in secondary school in the school year 1996/1997accounts for obese $(p=0.000)$ and thin children $(p=0.000)$, which is favor of secondary school children.

Conclusion Comparing the data between two school years, there were significantly more obese and thin children in 2010/2011 in primary schools, while in 1996/1997 there were more in secondary schools.

\section{EVALUATION OF NUTRITIONAL KNOWLEDGE AND ASSESSMENT OF DIETARY INTAKE OF SECOND GRADE SCHOOL CHILDREN}

doi:10.1136/archdischild-2012-302724.1450

${ }^{1}$ M Kherkheulidze, 'N Kavlashvili, 'E Kandelaki, ${ }^{2} \mathrm{~T}$ Manjavidze. 'Pediatrics, State Medical University; ${ }^{2}$ MoLSHA, Tbilisi, Georgia

Aim Assessment of nutritional knowledge and physical activity rate among the children and evaluation of their nutritional intake. Methods Cross-sectional study was conducted in randomly selected schools of Tbilisi. In each school was selected one group of the second grade children and their parents by cluster selection method. A population of 290 children aged 6-8 years and their parents were interviewed.

Results In general, the level of knowledge related to rich sources of nutrients was poor. The most of the children can't identify the role of calcium $(72.6 \%)$, proteins $(68.1 \%)$ and iron (84.6\%). Children prefer to eat foods they like $(71.8 \%)$, such as sweets and cakes, hamburgers and etc. The most of the children (83.3\%) have normal weight for age, underweight was revealed in $3.1 \%$, overweight in $12.3 \%$ and obesity in $1.4 \%$ cases. The assessment of dietary intake show, that intake of fruits and vegetables, as well as milk and milk products is quite low, while intake of bread and pastry, and sweets are quite high. Daily consumption of sweets was significantly higher in girls $(64.2 \%)$ than in boys $(47.5 \%)(p<0.01)$. Only $62 \%$ of children eat the breakfast, most children $60.4 \%$ view TV during the meal time or play computer games. The most of the children play the active games approximately $30-60$ minutes, quite often children play active games only 20-30 minutes.

Conclusion The dietary intake of children does not correspond to WHO recommendations. It is recommended to implement nutrition education programs for children an parents.

\section{NUTRIENT ADEQUACY OF THE DIETS OF UAE INFANTS AND TODDLERS}

doi:10.1136/archdischild-2012-302724.1451

${ }^{1} Y$ Abdulrazzaq, ${ }^{2} \mathrm{~S}$ Abdulla, ${ }^{3} \mathrm{G}$ Balhaj, ${ }^{4} \mathrm{~N}$ Nagelkerke. ${ }^{1}$ Paediatrics, UAE University, Al Ain; ${ }^{2}$ Paediattrics, Latifa Hospital, Dubai; ${ }^{3}$ Paediatrics, Al Ain Hospital; ${ }^{4}$ Community Medicine; UAE University, Al Ain, United Arab Emirates

Background Compared with other population subgroups, less is known about the dietary status of UAE infants and toddlers, especially how subgroups of different ages vary in their food consumption and nutrient intakes.

Objectives To assess the nutrient adequacy of the diets of UAE infants and toddlers 6 to 24 months of age.

Design Descriptive analysis of the usual nutrient intakes of infants and toddlers using 24-hour recall.

Subjects Families were recruited consecutively from the infants attending the preventive medicine department for immunization, until the number needed was attained. The study included UAE national infants (infants born to UAE national fathers) only. A sample of 1,000 infants and toddlers was selected from 2 cities, Dubai and $\mathrm{Al}$ Ain, in the UAE.

Results Percentage of breast feeding was found to be $49.6 \%$ in infants aged $6-11$ months and $38.4 \%$ at $12-24$ months. $65.6 \%$ percent of infants 6 to 11 months consumed cow's milk or camel's on a daily basis before the recommended age of 12 months or later. In most infants aged between 6 and 12 months had higher than the RDA levels of energy, protein, fats and carbohydrates, but surprisingly toddlers ingested less fat than RDA.

Conclusions More parents and caregivers can benefit from guidance about the introduction of developmentally appropriate, micronutrient-rich first solid foods such as iron-rich infant cereals, iron-fortified grain products, meats, soft fruits, and cooked vegetables and the importance of breastfeeding through the first year of life.

\section{OBESITY AND ALIMENTATION PATTERN IN ADOLESCENT HEALTH}

doi:10.1136/archdischild-2012-302724.1452

BE Popovici, M Mitrica. Pediatrics, Faculty of Medicine 'Transilvania' University Brasov, Brasov, Romania

Introduction Obesity is one of the most important health problems in children allover the world. The disease is detected more often nowadays and is corelated with lifestyle. 
Objective The aim of the study was to detect the prevalence of obesity in teenagers, the presence of the complications of the disease and alimentation pattern.

Material and method We had studied 162 teenagers from "Gr. Antipa" collegium, Brasov. the protocol of the study consist in clinical examination, body mass index calculoation (BMI), and a questionair regarding alimentation and phisical exercises.

Results In our study cohort 102 subjects (62.96\%) had BMI on the 95 th percentiles for agen and sex, $18(11.11 \%)$ on the 97 th percentiles and $7(4.3 \%)$ on the 99th percentiles. $152(93.82 \%)$ children had had alimentation disorders(sweets, soda, chips, fastfood almost dayly and fresh fruits ocasionaly). 110 children $(67.90 \%)$ had a sedentary life (TV, PC, no physical exercises). The main complications detected were hypertension (27\%), hypercholesterolemia (50\%), diabetes mellitus type $2(8 \%)$ and secundary amenohreea (6\%).

Conclusions Overweight and obesity is a reality in teenager cohort. More, there are present complications of the disease even in childhood. The main cause of the obesity is "life style" which include alimentation disorders and poor physical exercises. All the efforts should be made in education of the adolescents for the prevention of the obesity because an obese child shall became an obese young adult with degenerative cardiovascular pathology.

\section{USING BIA TO EVALUATE WEIGHT STATUS COMPARED TO BMI IN IRAINIAN CHILDREN WHIT AUTISM SPECTRUM DISORDERS}

doi:10.1136/archdischild-2012-302724.1453

${ }^{1} \mathrm{H}$ Salehi, 'S Shahmohammadlu, ${ }^{2 M}$ Mahmoudi, 'K Djafarian. 'Department of Nutrition and Biochemistry; ${ }^{2}$ Department of Biostatisticsand Epidemiology, School of Public Health, Tehran University of Medical Sciences, Tehran, Iran

Background and Aims Body composition is more important than body weight and body fat is a good guideline used to evaluate health Status better than sole weight. The aim of this study was to compare BIA and BMI to evaluate body weight status in autistic children and adolescents males in Iran.

Methods Eighty-one children and adolescents aged $7-13$ years old were selected randomly from 4 autism-specific schools in Tehran in 2011. Body composition of children was measured using BIA.

Results The findings revealed that on the basis of body mass index(BMI), $41.9 \%$ of children were normal weight $\left(5^{\text {th }}<\mathrm{BMI}<85^{\text {th }}\right)$, but $16 \%$ were overweight $\left(85^{\text {th }}<\mathrm{BMI}<95^{\text {th }}\right), 27.1 \%$ obese $\left(\mathrm{BMI}>95^{\text {th }}\right)$ and $14.8 \%$ underweight $\left(\mathrm{BMI}<5^{\mathrm{th}}\right)$, respectively. Based on percent body fat $(\mathrm{PBF}), 76.5 \%$ of children were normal body fat $\left(5^{\text {th }}<\mathrm{PBF}\right.$ $\left.<85^{\text {th }}\right), 3.7 \%$ of children were under the 5 th percentile, $12.3 \%$ were overweight $\left(85^{\text {th }}<\mathrm{PBF}<95^{\mathrm{th}}\right)$, and $7.4 \%$ were above the 95 percentiles.

Conclusions Although using BMI is simple and easy method for evaluating body weight status, measuring body fat by BIA is another alternative which give better picture of body composition in different health settings.

\section{IMPACT OF A CHAM JAM INTERVENTION ON PHYSICAL FITNESS IN ELEMENTARY SCHOOL STUDENTS}

doi:10.1136/archdischild-2012-302724.1454

M Reznik, PO Ozuah. Pediatrics, Children's Hospital at Montefiore, Albert Einstein College of Medicine, Bronx, NY, USA

Background and Aims CHAM JAM, a classroom-based physical activity intervention, has been effective in increasing physical activity levels in elementary school students. The objective if this study was to determine the impact of CHAM JAM on physical fitness.
Design and methods A cluster-randomized wait-listed controlled study at 6 Bronx, NY elementary schools. Two schools received CHAM JAM. We randomly selected a subset of 3rd grade students from intervention and control schools to measure physical fitness. Physical fitness testing included heart rate (HR) response to submaximal exercise assessed with a modified step test at baseline and 3 -months post-intervention. Students stepped up and down on step of calculated height for 3 minutes at a step cadence of 22 ascents/ minute. We measured HR pre-exercise, at peak exercise, and at 1-, 2-, and 3-min recovery period. Hierarchical linear models were used to evaluate differences in mean HR between and within the groups. Models controlled for gender, age, and BMI.

Results A total of 378 students participated (intervention, 176; control, 202). Between-group difference in HR change revealed that intervention group achieved significantly greater decrease in HR than control group.

Abstract 1454 Table 1 Adjusted differences in HR between groups

\begin{tabular}{lccc}
\hline Outcome & Difference Estimate & SE & p value \\
\hline HR pre-exercise & -4.89 & 1.25 & $<0.0001$ \\
HR peak & -3.67 & 1.76 & $<0.0375$ \\
HR 1 min & -4.16 & 1.48 & $<0.0052$ \\
HR 2 min & -4.95 & 1.32 & $<0.0002$ \\
HR 3 min & -5.21 & 1.29 & $<0.0001$ \\
\hline
\end{tabular}

Conclusions The CHAM JAM intervention improved physical fitness.

\section{PREVENTION OF CORONARY HEART DISEASE RISK FACTORS IN CHILDREN - THE ROLE OF HEALTHY NUTRITION}

doi:10.1136/archdischild-2012-302724.1455

${ }^{1} \mathrm{M}$ Kelmendi, ${ }^{2} \mathrm{R}$ Bejiqi, ${ }^{2} \mathrm{R}$ Retkoceri, ${ }^{2} \mathrm{~A}$ Batalli-Kepuska, ${ }^{2} \mathrm{H}$ Bejiqi. 'Cardiology; 2University Children's Hospital, Prishtina, Kosovo

Coronary heart disease (CHD) is the commonest cause of morbidity and mortality worldwide. Our country, as a developing one is facing also with many, "new fashioned" diseases, which are becoming epidemic in developed world, such as: obesity, diabetes mellitus, hypercholesterolemia, stress and unhealthy diet.

Objective The aim of this study is

1. To present food patterns in schoolchildren in our region and

2. To stress the role of healthy nutrition in the prevention of CHD.

Methods Two hundred schoolchildren, aged from 7-15 years, examined at University Children's Hospital, are included in this study. They are selected at random and mostly suffer from respiratory infections, throat infections, rheumatic fever, etc. Except history, physical examination, laboratory and anthropometric measures, an questionnaire regarding to food habits was filled by all patients.

Results Of 200 examined children, there were 150 (75.0\%)with normal weight (<97 percentile), $36(18.0 \%)$ underweight $(<3$ percentile) and $14(7.0 \%)$ overweight ore obese ( $>97$ percentile). There were $10(5.0 \%)$ children with dislypidaemia and $6(3.0 \%)$ with hypertension. The questionnaires analysis revealed many unhealthy habits: $75.0 \%$ prefer processed and fast food, $85.0 \%$ sweetened fruit drinks and soda. On the other hand, the consumption of healthy food, such as: milk, honey, fruits, whole grains, vegetables, functional foods, fish etc is very low.

Conclusion This paper underlines the link between food and health, especially in children; they, as a very vulnerable segment of population are often "victims" of food industry which offer them: high content of salt, sugar, trans fat. 